\section{Urologia \\ Internationalis}

\section{Elijah O. Kehinde ${ }^{a}$ \\ Jehoram T. Anim ${ }^{\text {b }}$ \\ Parsotam R. Hira ${ }^{c}$}

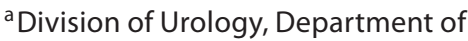
Surgery, bection of Morbid Anatomy, Department of Pathology, and 'Section of Parasitology, Department of Microbiology, Faculty of Medicine, Kuwait University, Safat, Kuwait
Urol Int 2008;81:1-13

DOI: $10.1159 / 000137633$

\title{
Parasites of Urological Importance
}

Key Words

Parasites • Genitourinary tract • Epidemiology • Diagnosis • Treatment

\begin{abstract}
With the world increasingly becoming a global village, transnational and transcontinental migration has become the order of the day. It is expected that migrants will take with them some diseases (including parasites) which are normally endemic in their countries of origin, to their host countries. Similarly, environmental changes that result from development of water resources, global warming, growth and migration of population can facilitate the spread of parasites. In this review we describe the epidemiology, presentation, diagnosis and treatment options of parasites that urologists may encounter. Notably among these parasites are Schistosoma haematobium, Echinococcus granulosus, Wuchereria bancrofti and Onchocerca volvulus.
\end{abstract}

Copyright $\odot 2008$ S. Karger AG, Base

\section{Introduction}

\section{Parasites}

Parasitism includes any reciprocal association in which one species depends upon another for its existence. This association may be temporary or permanent. The harbouring species, known as the host, may show no harmful effects or may suffer from various functional and organic disorders.

The endemicity of a parasite depends upon the presence and habits of a suitable host(s) and upon easy escape from the intermediate or definitive host. Parasites with simple life cycles are most likely to have a more cosmopolitan distribution than those with complicated life cycles. Climatic as well as economic and social conditions of the host affect the distribution of human parasites [1, 2]. Inadequate individual and community sanitation, low standards of living and ignorance favour the spread of parasitic diseases.

The life cycle of a parasite may involve survival and development in the external environment and in 1 or more hosts. It may be relatively simple or it may be complicated, with numerous morphological forms and developmental stages [3-5]. In the external environment,

E.O. Kehinde, MBBS, FRCS, MD

Department of Surgery (Division of Urology), Faculty of Medicine

Kuwait University, P.O. Box 24923

13110 Safat (Kuwait)

Tel. +965 531 9475, Fax +965 531 9597, E-Mail ekehinde@hsc.edu.kw 
Table 1. Helminthic parasitic diseases of the genitourinary system

\begin{tabular}{|c|c|c|c|c|}
\hline Type of organism & Species & Intermediate host & Definitive host & Disease \\
\hline \multirow[t]{2}{*}{$\begin{array}{l}\text { Cestodes } \\
\text { (tapeworm) }\end{array}$} & $\begin{array}{l}\text { Echinococcus granulosus } \\
\text { Echinococcus multilocularis }\end{array}$ & sheep & dogs, fox & hydatid disease \\
\hline & Taenia solium & pig & human & $\begin{array}{l}\text { cysticercosis from encysted larval } \\
\text { forms (cysticercous cellulosae) }\end{array}$ \\
\hline $\begin{array}{l}\text { Trematodes } \\
\text { (flukes) }\end{array}$ & $\begin{array}{l}\text { Schistosoma haematobium } \\
\text { Schistosoma mansoni } \\
\text { Schistosoma japonicum }\end{array}$ & snail & human & $\begin{array}{l}\text { bilharziasis or } \\
\text { schistosomiasis }\end{array}$ \\
\hline \multirow[t]{3}{*}{$\begin{array}{l}\text { Nematodes } \\
\text { (roundworms) }\end{array}$} & & $\begin{array}{l}\text { mosquitoes: Anopheles sp., } \\
\text { Culex sp., Aedes sp. }\end{array}$ & human & lymphatic filariasis \\
\hline & Onchocerca volvulus & black flies (Simulium sp.) & human & onchocerciasis \\
\hline & Dioctophyme renale & oligodrates (Millipedes) & $\begin{array}{l}\text { carnivores, } \\
\text { rarely human }\end{array}$ & dioctophymesis \\
\hline
\end{tabular}

Table 2. Geographical distribution and types of infections caused by different species of schistosoma

\begin{tabular}{lll}
\hline Type of schistosoma & Geographical distribution & Type of infection \\
\hline S. haematobium & $\begin{array}{l}\text { Africa (Egypt, Sudan, Zambia, Nigeria, South Africa), } \\
\text { Middle East (Saudi Arabia, Iraq, Iran) }\end{array}$ & $\begin{array}{l}\text { urinary organs } \\
\text { (bladder, ureters, prostate, seminal vesicles) }\end{array}$ \\
\hline S. mansoni & Africa, Caribbean Islands, South America (Brazil) & mainly colon \\
\hline S. japonicum & Far East (China, Korea, Philippines) & mainly small intestine \\
\hline
\end{tabular}

the parasite may be quiescent in the form of resistant eggs or cysts. When taken up by an appropriate host it may undergo active growth and metamorphosis. As the life cycle becomes more complicated, the chances of parasite survival decrease, but highly developed reproductive organs and multiplication at some stage of the parasite's life cycle offset the hazards of a complex life history $[4,5]$.

\section{Parasitic Infections of the Genitourinary Tract}

The most important parasitic diseases involving the genitourinary system in humans are helminthic and include schistosomiasis, hydatid disease and filariasis. These and other helminthic diseases are summarised in table 1. Non-helminthic parasites that can infect the genitourinary tract include protozoans like Trichomonas vaginalis, Plasmodium falciparium and Entamoeba histolytica.

\section{Schistosomiasis}

Schistosomiasis is also known as bilharziasis after the German pathologist Theodore Bilharz who first described the disease in 1852. Urinary bilharziasis may affect up to 100 million people in endemic regions of Africa $[2,5]$. The causative parasite Schistosoma haematobium, is one of the main schistosome species whose primary host is man. The other species include $S$. mansoni, which can coexist with $S$. haematobium and is prevalent in Africa, South America and some Caribbean Islands, while S. japonicum is found only in the Far East. The latter 2 species are responsible for the intestinal and hepatic forms of the disease. S. mansoni causes infection in the colon, while $S$. japonium causes infection in the small intestines (table 2). Any area of fresh water that can support the intermediate host, an aquatic snail of the $\mathrm{Bu}$ linus species, is a potential source of infection, once the schistosome ova have been deposited in the water through contamination with urine from an infected individual [ 1 , $2,5]$. 
Cercariae penetrate human skin; enter circulation

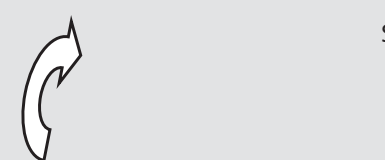

Cercariae released from sporocysts into surrounding water

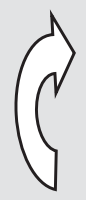

Formation of sporocysts within host liver (snail)

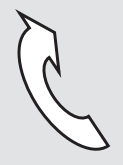

Penetration of snail (Bulinus sp.)

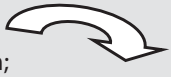

Systemic infection (liver, pelvic veins);

Cercariae develop into adult flukes

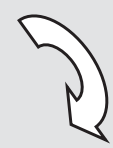

Adult pairs in pelvic veins deposit ova into bladder wall
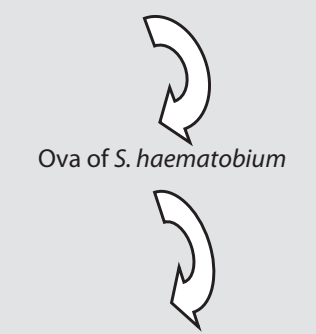

Ova voided in urine; hatched as ciliated miracidia

Fig. 1. Life cycle of S. haematobium.

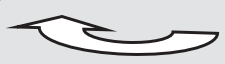

The morbidity of urinary bilharziasis relates little to the acute infection, which is now easily and safely treated with effective oral antischistosomal agents. This is due more to the lingering sequelae of host reaction to the eggs of the parasite, manifested by progressive urinary tract dysfunction and the potential development of bladder carcinoma. There have been several approaches towards controlling infestation, but these have failed either because of difficulties with public education or due to the overriding need to preserve local ecological milieu. Bilharziasis is therefore likely to remain a major health problem for the foreseeable future in these endemic areas [6].

\section{Life Cycle of Schistomiasis}

The adult worms reside mainly in the retrovesical and periprostatic plexuses of veins, where the eggs are deposited, deep in the wall of the bladder. Each egg develops a miracidium within a week of being released from the worm in the body and excites an intense local histocytic tissue reaction that carries it through the lamina propria and urothelium to be shed into the bladder lumen, together with extravasated blood. The characteristically oval and terminally spined eggs are readily identified on urine microscopy.

When urine containing ova reaches a body of fresh water, the eggs hatch and the released miracidia swim actively around in search of a suitable snail host. The larval form of $S$. haematobium develops exclusively within Bulinus spp., where it matures in about 30 days into fork-tailed cercariae which are released into fresh water. The released cercariae which are actively motile in water are able to penetrate intact human skin to continue the sexual phase of the life cycle. The young adult forms, or schistosomulae, gain access to the venous or lymphatic systems and are thence carried through the heart and lungs into the portal vein. Here, the adult worms mature within a few weeks, the female being carried in the gynaecophoric canal of the male during the final stage of their odyssey down to the pelvic veins (fig. 1). 
Fig. 2. Intravenous urogram in a 53-yearold Egyptian man with right loin pain. A Plain X-ray of kidneys, ureters and bladders showing classical ring calcification of the bladder, calcifications of lower third of both ureters and a calculus at right vesicoureteric junction. B After contrast injection, the X-ray shows moderate right hydronephrosis with an obstructing calculus at right vesico-ureteric junction and a small contracted bladder. These features are indicative of severe vesical schistosomiasis and a high risk of developing subsequent squamous or transitional cell carcinoma of the bladder.
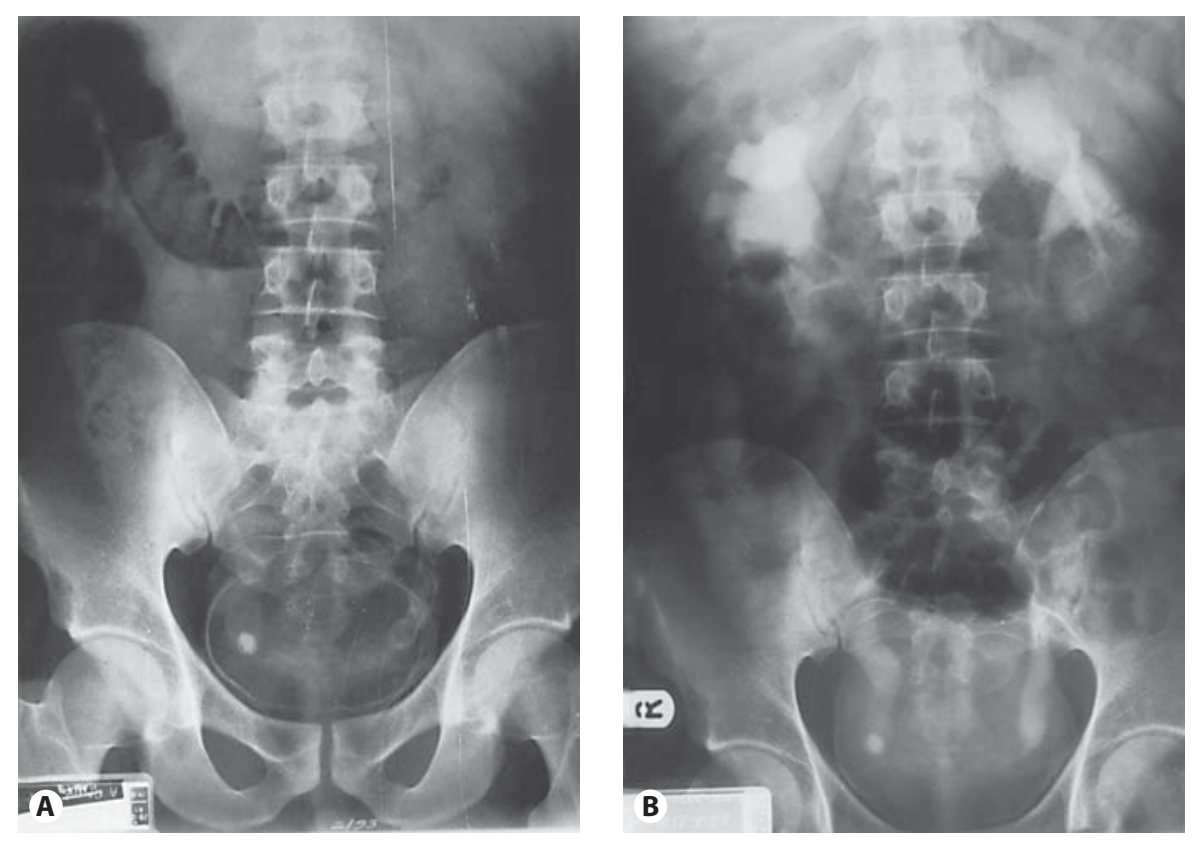

\section{Pathology and Clinical Features}

Urinary tract disease is a specific trait of infection with S. haematobium [7]. Haematuria is the first sign of established disease, appearing 10-12 weeks after infection. Chronic disease is caused by granulomatous inflammation that occurs in response to the deposition of eggs in tissue. Dysuria and haematuria are common in both early and late disease. Late manifestations of the disease include proteinuria (often in the nephrotic range), calcifications in the bladder (fig. 2), obstruction of the ureter, renal colic, hydronephrosis and renal failure. Secondary bacterial infection is frequent. On cystoscopy, sandy patches (areas of roughened bladder mucosa surrounding egg deposits) are often visible and are pathognomonic. Structural abnormalities of the urinary tract can occur in children [8].

The association between $S$. haematobium infection and squamous cell carcinoma (SCC) of the bladder has been the subject of intense research and debate. Squamous cell carcinomas of the bladder associated with $S$. haematobium tend to be well differentiated and to spread locally (fig. 3). In hyperendemic areas such as Egypt, SCC of the bladder accounts for $18-28 \%$ of all cancers, with an incidence of 10.8 per 100,000 population $[9,10]$. Male smokers appear to be at particular risk [10]. The association appears to be consistent in many sub-Saharan nations as well [8]. However, large autopsy series have failed to demonstrate a consistent association with a particular type of tumour [11], and SCC of the bladder is prevalent in some countries that have a very low prevalence of $S$. haematobium infection or none at all. S. haematobiumassociated bladder cancers are often associated with mutations of the p53 and cyclin-dependent kinase inhibitor 2 tumour suppressor genes [7]. At present, there is sufficient evidence to conclude that $S$. haematobium has a role in causing some types of bladder cancer.

S. haematobium infection causes genital disease in approximately one third of infected women $[8,12]$. Isolated internal genital disease is less frequent. Vulval and perineal disease may be hypertrophic, ulcerative, fistulous or wart like and may be mistaken for other genital infections, particularly condylomata lata [13]. Tubal infertility may be a late complication. Vulval schistosomiasis may also facilitate the transmission of human immunodeficiency virus $[12,14]$.

\section{Bladder}

Both transitional cell carcinoma (TCC) and SCC are associated with schistosomal infection of the bladder with a much higher incidence of SCC in endemic areas. Regional differences are difficult to explain. In Egypt a $25 \%$ incidence of cancer has been reported. In Sudan a much lower incidence of $3.1 \%$ is noted. In Zambia the carcinoma rate is $9 \%$, though still mostly squamous. Wallace [15] has shown in Saudi Arabia that prolonged involvement with schistosomiasis resulting in calcification of the bladder is associated with early death, pre- 

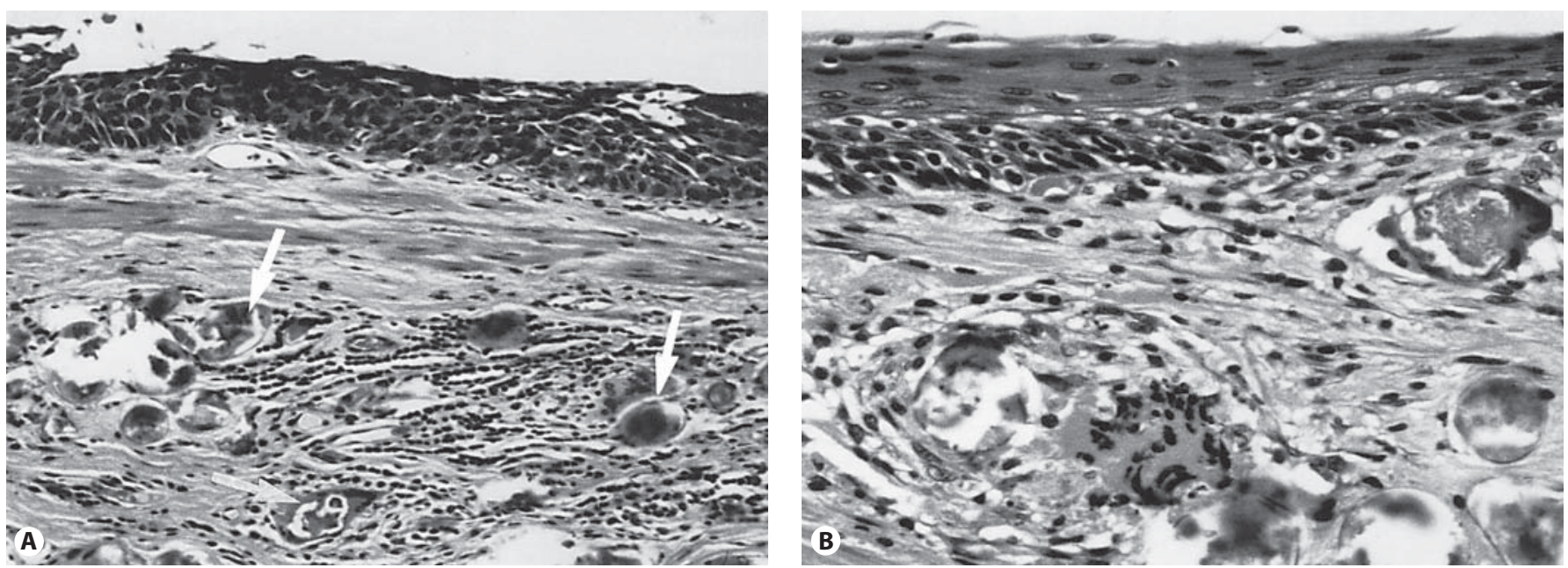

Fig. 3. A Photomicrograph of bladder mucosa showing schistosoma ova (white arrows) in the wall with surrounding chronic inflammation. B Another area of the same bladder showing squamous metaplasia of urothelium with underlying granulomatous inflammation around schistosoma ova. C Another area of the same bladder showing squamous cell carcinoma (right side of picture) and adjacent collection of schistosoma ova with surrounding chronic inflammation.

sumably from carcinoma. A possible explanation for these differences is the co-existence of other bladder carcinogens in some areas. Ingested nitrate fertilizers have been shown recently to be converted to nitrosamines by enzymes present in the bladder, especially if the urine is infected by Escherichia coli. Nitrosoamine compounds are carcinogenic and this may explain some of the regional differences. Women are protected to a greater degree than expected, even allowing for the social factors which limit the exposure of women to the disease (they do not work in the fields in Egypt). This protection could be due to a hormonal effect but this requires confirmation.

\section{Other Organs}

The seminal vesicles are often involved in bilharziasis, resulting in 'honeycomb' calcification on X-rays [16]. Prostatic involvement may produce backache and blad-

Parasites in Urology

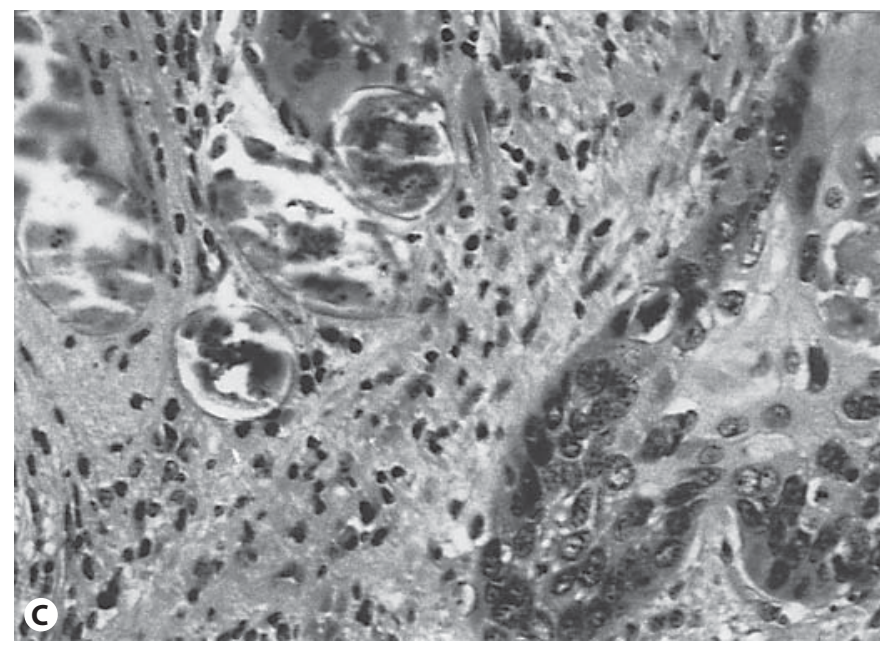

der outflow obstruction. Prostatic calcification may also be seen on ultrasound of the prostate. Digital rectal examination findings may be suggestive of prostate cancer as the prostate and seminal vesicles, when involved, may feel hard and nodular on rectal examination [16]. Ureteric involvement, especially of the lower third of the ureter, may produce pseudotubercles, strictures and calcification with resultant obstructive uropathy. Involvement of the middle third of the ureter can occur via the superior and inferior mesenteric veins. The upper third of the ureter and the pelvi-ureteric junction are only seldom affected, but when affected may lead to the 'drooping kidney' appearance of the affected renal unit [17]. In endemic areas, ureteric involvement by schistosomiasis is a frequent cause of hydronephrosis and varying grades of renal impairment. Rarely, the kidney itself may be involved and glomerulonephritis may result. Epididymitis and orchitis can occur, as can stricture of the urethra 
which may be palpable, simulating Peyronie's disease. Scrotal, perineal and vulval nodules have also been reported.

\section{Diagnosis}

Demonstration of ova in urine is a rapid, non-invasive and reliable method of diagnosis. Terminal urine samples taken at mid-morning are most appropriate. The use of nucleopore filters is recommended. 'Squash' specimens of biopsy material are helpful and serological investigations are now proving more reliable, especially the enzyme-linked immunosorbent assay [18-20]. A recent development is an immunoblot assay for detection of the adult worm antigen [20], which reportedly has $95 \%$ sensitivity and $100 \%$ specificity. In late stages, calcification may be seen on plain X-ray and computed tomography scanning and papilloma formation and ureteric involvement may be seen on intravenous urography (fig. 2). Intravenous urography may also show a filling defect if SCC or TCC has complicated the disease. Bladder biopsies may also show characteristic schistosoma eggs on histology (fig. 3). Additional supportive laboratory evidence of schistosomiasis might include evidence of peripheral blood eosinophilia [5].

\section{Treatment}

\section{Medical}

Praziquantel, a pyrazinoisoquinoline derivative, is the mainstay of treatment and a critical part of communitybased schistosomiasis control programs. Since its discovery in the mid-1970s, its safety and efficacy have ensured its widespread use [21]. It is absorbed well but undergoes extensive first-pass hepatic clearance. Praziquantel is secreted in breast milk, it is metabolized by the liver and its (inactive) metabolites are excreted in the urine. The drug's precise action on adult worms is unknown. It appears to cause tetanic contractions and tegumental vacuoles, causing worms to detach from the wall of the vein and die. In animal models, the presence of host antibodies has been shown to be critical for its efficacy [22]. Optimal therapy requires $2-3$ doses of $20 \mathrm{mg} / \mathrm{kg}$ given 6 $8 \mathrm{~h}$ apart with food. Re-examination of urine 1 month after treatment is recommended in order to assess efficacy [5]. Praziquantel reliably cures $60-90 \%$ of patients and substantially decreases the worm burden and egg production in those who are not cured. Patients who con- tinue to shed viable eggs should be re-treated with the same dose; the second treatment is usually successful. The urinary tract disease from S. haematobium infection $[9,23]$ may improve after successful treatment if re-infection is avoided. The efficacy of praziquantel is unaltered in patients who are co-infected with human immunodeficiency virus type 1 [24]. Metrifonate is an alternative drug for S. haematobium infection, but is no longer available commercially [5].

Praziquantel is a poor choice for chemoprophylaxis because of its short half-life (1-1.5 h) and because it cannot kill schistosomula (the migrating larvae) that are 321 days old. Artemether $(6 \mathrm{mg} / \mathrm{kg})$, which is well known for its antimalarial activity, kills schistosomula during the first 21 days in the body. Therefore, it should kill all immature schistosomula if it is given every 2 weeks [25]. Artemether is also active against the other schistosome species that infect humans $[26,27]$. Combining artemether with praziquantel appears to produce a synergistic killing of adult worms [28]. The prospects seem good for prophylaxis with artemether in high-risk groups in areas where schistosomiasis is endemic, such as flood relief workers, tourists and fishermen [29]. The doses required are lower than those required for treatment of malaria, but it is unlikely that artemether would be used in areas where malaria is endemic, because such use might lead to the selection of artemether-resistant Plasmodium falciparum.

Resistance to praziquantel may be emerging after nearly 30 years of intensive use. In regions of Egypt and Kenya where there has been heavy exposure to praziquantel, there are reports of S. mansoni and S. haematobium infections that are not responsive to multiple courses of treatment [30,31]. There is some laboratory evidence suggesting that these drug-tolerant worms may have altered tegumental architecture, which could limit the effectiveness of the drug [31]. So far, however, patients in many communities have undergone multiple courses of treatment over a period of 10 or more years without a demonstrable loss of efficacy [32]. Because worm reproduction in the mammalian host is sexual and the generation time is relatively long, resistance is likely to take many years to become an important clinical and public health issue $[5,32]$.

\section{Surgical}

Despite effective medical treatment, secondary infection and SCC of the bladder, bladder contracture and bladder neck stenosis may well require surgical correction by cystoplasty, urinary diversion, bladder neck inci- 
sion or bladder neck V-Y plasty [33]. The type of diversion chosen is often determined by ethnic and social considerations rather than by technical factors [33]. Mild ureteric strictures can be treated with dilatation, internal ureterotomy and a period of 'J' stenting [34]. Moderate to severe ureteric cicatrisation and stenosis with rigidity and reflux may well require re-implanatation of the ureter, possibly with a psoas hitch procedure or a Boari/Ockerblad flap. Sometimes an ileal replacement of the diseased ureter is necessary. To overcome some of the problems associated with using the ileum to replace a long segment of ureteric stricture, Ghoneim and Ali-El-Dein [35] have reported their experience of replacing the ureter by an ileal tube using the Yang-Monti procedure. Preliminary reports by these authors confirm the versatility of using this technique in patients with schistosomiasisinduced strictures of long segments of the ureter [36]. Antireflux operations are disappointing in the presence of extensive fibrosis and tissue thickening.

Apart from ureteral strictures, the other significant complications of schistosomiasis which may require surgical intervention are contracted bladder, bladder outlet obstruction and bladder cancer.

\section{Contracted Bilharzial Bladder}

Bilharzial contracted bladder is the outcome of severe and prolonged infection. Sayegh and Dimmette [37] reported that this serious complication occurred in $0.6 \%$ of their urological admissions. Affected patients are usually men in their third or fourth decade of life. The presenting symptoms are intractable frequency, painful micturition and urge incontinence. Cystoscopy under a general anaesthetic will readily show reduced bladder capacity. Surgery is indicated in cases where the bladder capacity is reduced to $<100 \mathrm{ml}$. The procedure of choice is augmentation cystoplasty, using either ileum or colon [38, 39].

\section{Bladder Outlet Obstruction}

Shokeir et al. [40] reported that bladder neck obstruction was a significant feature in $7.5 \%$ of patients with complicated bilharzial cystitis. The patients, usually men aged 20-40 years, present with symptoms of cystitis and difficulty on micturition. Calculous disease and secondary bacterial infection are sometimes coexisting findings. The diagnosis is based on urodynamic evaluation with simultaneous recording of the voiding pressure and flow rate. Endoscopic incision of the bladder neck provides the best functional results [41].

Parasites in Urology
Carcinoma in the Bilharzial Bladder

The association of bladder cancer with urinary bilharziasis determines distinct clinicopathological behaviour [42]. The peak age of incidence is between the third and fifth decades; the male: female ratio is 4:1 [33]. Patients present with symptoms of cystitis, painful micturition, frequency and haematuria. Urography may reveal an irregular filling defect in its cystographic phase. The diagnosis depends upon cystoscopy, biopsy and careful bimanual examination under anaesthesia. There are several treatment options.

Endoscopic Resection. In view of the bulk and advanced stage of these tumours, transurethral resection appears unfeasible for definitive treatment. Endoscopic resection is currently limited to obtaining biopsy material for histopathological diagnosis and evaluation [33].

Segmental Resection. Local resection is only feasible in certain conditions, that is, if the tumour is solitary, does not involve the trigone, its size allows excision with adequate safety margin and the rest of the bladder is free of any associated precancerous lesion. Very few patients with carcinoma of the bilharzial bladder satisfy these criteria [33].

Radical Cystectomy. Because of the pathology and natural history of the disease, radical cystectomy and some form of urinary diversion provide the logical surgical approach to most cases with resectable tumours [33, 42]. The extent of excision includes the bladder with its perivesical fat, peritoneal covering, prostate and the seminal vesicles, together with the distal common iliac, internal iliac and external iliac lymph nodes. In the female bladder, resection includes the urethra, uterus and upper two thirds of the vagina, with pelvic cellular tissue and the aforementioned lymph nodes [33]. Unlike TCC of the bladder, SCC does not respond to intravesical chemotherapy or external beam radiotherapy [33]. Hence, once the disease cannot be controlled by transurethral resection of bladder tumour or is invasive, the best treatment option is radical cystectomy with ileal neo-bladder formation where feasible or ileal conduct.

\section{Hydatid Disease Involving the Kidneys}

Hydatid disease of the kidney is a very rare condition caused by the larval stage of Echinococcus granulosus. The cestode Echinococcus responsible for this disease is an intestinal tapeworm of dogs, wolves and foxes. Endemic areas for the pastoral form of this disease, such as Mediterranean countries, New Zealand, South America, 


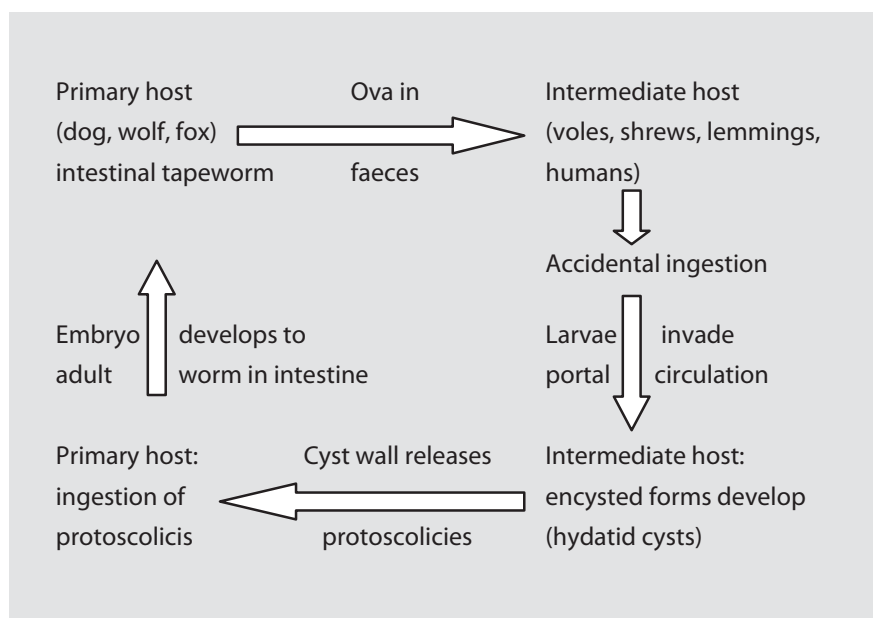

Fig. 4. Life cycle of E. granulosus.

Africa, Australia, Middle East and some parts of Europe, maintain a reservoir of disease by allowing dogs free access to the raw offal of sheep and cattle casually butchered on the farm or village, sometimes for ritual sacrifice. The life cycle of the parasite is shown in figure 4 .

In the aquatic form the usual secondary host is the sheep, cattle, moose or caribou, and when this form of the disease affects man it tends to run a relatively benign course, usually with the development of small numbers of unilocular cysts. Rarely, the species involved is Echinococcus multiocularis which has a much more invasive larval form with a very high mortality [43].

\section{Cyst Formation}

Clinical hydatid disease in man is due to the effects of the development of cysts. Hydatid cysts can develop in virtually any organ, including the testis [44] and the ovary [45], but since after ingestion and initial development the larval form of the organism must first penetrate the intestinal mucosa and travel via portal veins to the liver, the most frequent site of primary disease is hepatic; later, pulmonary or systemic spread may develop. The innermost lining of a cyst is the germinal layer which buds brood cysts from which scolices develop. Mature brood cysts become daughter cysts.

From the secondary hosts, daughter cysts or scolices ingested by dogs give rise to intestinal tapeworms in the dogs. The shed ova may in turn be accidentally ingested by man. Eradication of the disease as a whole is by breaking the life cycle, by refusing access of dogs to untreated

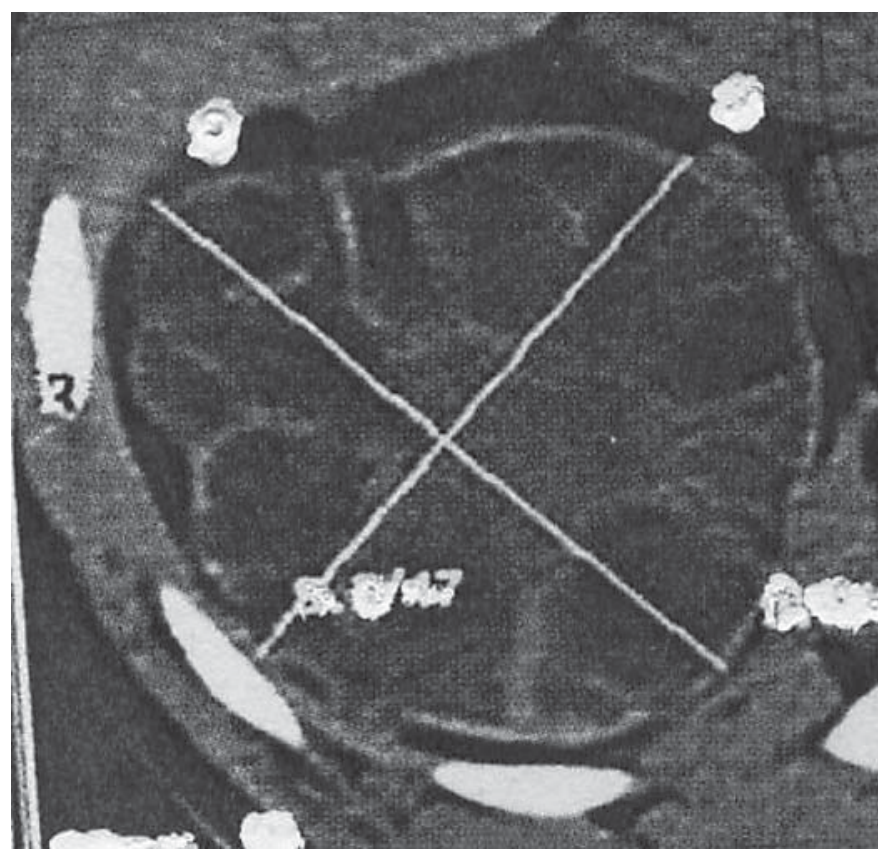

Fig. 5. Computed tomography scan appearance of hydatid cyst involving the kidney showing multiple small, thin-walled cystic lesions with a typical peripheral location giving the so-called rosette appearance.

offal, especially from sheep. This should be easy, but public health education is often misunderstood and only slow progress is being made. Treating dogs for the infection is a reliable alternative.

\section{Diagnosis}

The patient typically presents with flank pain or an abdominal mass $[46,47]$. The presence of a cyst involving the kidney or bladder may be suggestive of the disease in a patient from an endemic area who shows a space-occupying lesion on radiological or ultrasound investigation. Radiological features suggestive of hydatid disease of the kidney include: (1) curvilinear calcification in a part of the kidney on plain X-ray of kidneys, ureters and bladders, and (2) homogenous, multicystic, hypoechoic mass with septations on ultrasound of the kidneys and computed tomography scan appearance of a thick-walled cystic mass in the kidney with typical peripheral location giving the so-called rosette appearance as illustrated in figure $5[48,49]$.

Whether the cyst is infective, growing actively or aborted by host response is impossible to judge accurately at first sight. In most cases, it will be wise to assume that the cyst 
fluid is infective and that spillage of the fluid onto normal tissue must be avoided at all costs. Serological testing includes methods such as indirect haemagglutination, immunofluorescence and immunoelectrophoresis, but the development of a suitable purified antigen has been a problem in immunological diagnosis. As a result, cross reactions have been noted especially with Cysticercus antibodies, and serology must not be taken as the sole diagnostic criterion. Approximately $2 \%$ of patients with hydatid disease will show renal involvement [50]. This will have developed from a larva reaching renal parenchyma via the systemic circulation. Pelvic cysts affecting the bladder occur in 5\% of these patients and transcoelomic spread from a ruptured hepatic cyst is the usual source in these cases. Patients with bladder involvement may present with frequency of micturition, urinary retention or obstructive azoospermia [51]. A cyst may die and calcify. By itself, a cyst causes little trouble except through pressure effect, so there is much to be said for a period of observation and surgical restraint. Renal function is generally well maintained and it is rare for a hydatid cyst to rupture into the calyceal system and discharge into the urine. If rupture of a cyst does occur, an intense allergic reaction may follow with pain, fever and a high eosinophil count.

\section{Hydatid Disease of Other Genitourinary Organs}

Like schistosomiasis, hydatid disease can affect virtually any organs in the body, but particularly other genitourinary organs like the prostate, seminal vesicles, testes, bladder and ovary $[44,45,51]$. In areas of the world where hydatid disease is endemic, a high index of suspicion is required whenever a patient presents with an unusual mass. We agree with Adewunmi and Basilingappa [45] that a diagnosis of hydatid disease should be considered whenever a septate pelvic mass is found in patients in or originally from endemic areas.

\section{Treatment}

\section{Medical}

Many clinical trials have shown that the benzimidazole compound albendazole is useful in treatment [52-54]. It has been possible to measure the levels of albendazole in cyst fluid after a period of treatment to assess penetration into intact cysts, and therapeutic levels can be achieved. Cysts become smaller, osmotic pressure falls so the cyst becomes softer and floppy and the cyst membrane may separate, indicating that the cyst is dying. However, to achieve the best benefit, treatment may need to be continued for many months and the patient will need to be monitored for the possibility of hepatotoxicity. Albendazole is given in a dose of $10 \mathrm{mg} / \mathrm{kg} /$ day. Unfortunately, in some patients who have been treated for years and who appear to have had a good response, when treatment is discontinued there is evidence that the disease slowly regains its vigour and may eventually recur $[54,55]$.

While albendazole can penetrate the intact cyst, it is a relatively weak antihelminthic. A stronger agent is available which is useful at the time of surgery. Praziquantel in a dose of $40 \mathrm{mg} / \mathrm{kg} /$ day given for 1-2 weeks postoperatively will work well to eradicate infective particles spilled or released into the circulation. Unfortunately, it does not penetrate intact cysts. Even stronger still are chemical agents such as $0.5 \%$ silver nitrate $[54,55]$ or $2.5 \%$ formalin, which can be instilled directly into cysts after extraction of some of the fluid. Exposure of the germinal membrane to such an agent will sterilize the cyst in 1-2 min.

Ideally, therefore, patients should be treated with albendazole for at least 3 months and possibly longer, prior to evacuation of the cysts. Patients are brought to surgery with hydrocortisone cover to avoid serious allergic reactions and surgical evacuation is best done by using a method which avoids spillage.

\section{Surgical}

Wherever possible, surgery is still the mainstay of therapy of hydatid disease involving the kidneys and the objective is to remove all infective elements with the minimum of trauma and no contamination. If possible, the cyst should be excised, if necessary, at the same time removing some normal tissue such as partial nephrectomy or nephron-sparing pericystectomy $[45,46,49]$. Nephrectomy is reserved for destroyed kidneys [45]. If the lesion in the kidney is small, asymptomatic and the cyst walls calcified, it has been advocated that such patients need no treatment [55]. At surgery, the surrounding tissue must be protected by covering with saline-soaked pads and care must be taken to ensure no spillage occurs to prevent seeding and secondary infestation. In theory, all that is necessary is to remove the infective cyst fluid and the germinal layer and this must be done by a method that avoids contaminating surrounding tissues. Where field contamination by cyst contents has occurred during surgical treatment, prophylactic use of albendazole is recommended to prevent recurrence.

Laparoscopic evacuation of the hydatid cysts with excision of the redundant cyst and pericyst tissue has been 


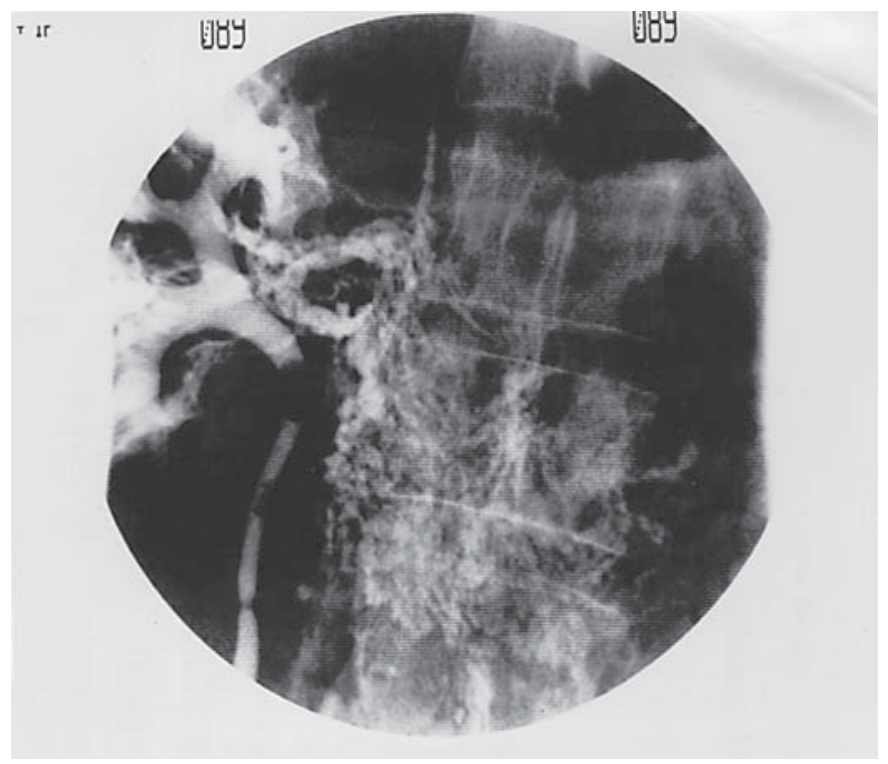

Fig. 6. Retrograde pyelogram showing abnormal communication between the pelvi-calyceal system and the para-aortic lymphatic system.

reported and, recently, with the development of interventional radiology it has become evident that percutaneous drainage of such cysts is a possibility [56]. Successful treatment has been performed with short-term follow-up with these 2 methods [56]. However, as recurrent cysts caused by seeding during any of these minimally invasive procedures may not become evident for 5 years or more, only long-term follow-up of these methods will prove their value.

\section{Genitourinary Diseases Caused by Wuchereria bancrofti}

W. bancrofti can cause lymphatic obstructions and often results in 2 types of disorders affecting the genitourinary tract, namely chyluria and elephantiasis of the scrotum.

\section{Chyluria}

$W$. bancrofti accounts for $90 \%$ of cases of lymphatic filariasis in humans and is widespread throughout the tropics and subtropics. Chyluria occurs after rupture of the lymphatic varix into the urinary collecting system. Recurrent parasitic attacks result in the destruction of the lym-

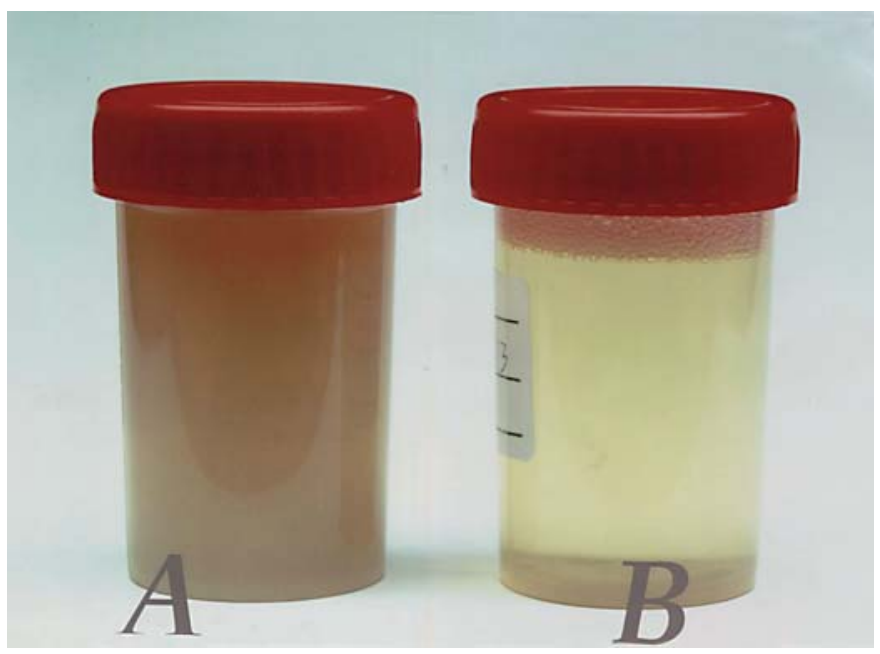

Fig. 7. Milky urine (A) passed by a patient with chyluria compared with normal-coloured urine (B).

phatic wall which subsequently affects the retroperitoneal lymphatic vessels. Increased intralymphatic pressure in the retroperitoneal lymphatic vessels may result in valvular incompetence of the lymphatics in the lumbar and pelvic regions. The disturbances in flow dynamics result in the retrograde flow of chyle, producing lymphatic fistulous communication between the lymphatic and urinary collecting systems [57]. Retrograde pyelogram showing the abnormal communication is often diagnostic (fig. 6).

The patient typically complains of passing 'milky' urine (fig. 7). As long as chyluria is intermittent, the disease is considered mild, but in more severe cases, chyluria is continuous and can lead to nutritional deficiency [57].

\section{Treatment}

In mild cases, no treatment is required. Moderate to severe chyluria often require medical treatment using albendazole. Medical treatment is rarely effective in fullblown cases of chyluria. Retrograde injection of sclerotherapeutic agents ( $5 \%$ povidone iodine or $0.5 \%$ silver nitrate) into the ureter and pelvi-calyceal system of the affected side have been found to be palliative in moderate cases of chyluria. The treatment regimen consists of 5-10 $\mathrm{ml}$ of sclerosants instillation weekly for about 4 weeks or three times daily (TDS) for 2-3 days [58]. Such regimens have been reported to be $60-70 \%$ successful in mild to moderate cases of chyluria [57]. However, the most effective treatment for severe chyluria is renal pedicle lymphatic disconnection. This can be achieved either by open surgery or laparoscopically $[56,59]$. 


\section{Elephantiasis of the Scrotum}

This is due to obstruction of the lymphatic vessels of the penis or groin by the filarial worm $W$. bancrofti with superadded infection and lymphangitis. It is often the cause of massively enlarged scrotum in the tropics. The characteristic appearance of the external genitalia makes diagnosis easier and can be confirmed if necessary by detection of filaria antigen in blood. In patients who have not been to the tropics, and in whom investigations have failed to show evidence of previous filarial infection, the diagnosis of idiopathic scrotal oedema should be considered [60].

\section{Treatment}

There is no effective medical treatment for the disease. However, if detected early, the drug of choice is diethylcarbamazine $0.5-2 \mathrm{~g} / \mathrm{kg}$, TDS for 3 weeks or albendazole. The treatment of large scrotal elephantiasis is surgical irrespective of the aetiology $[60,61]$. In advanced cases, excision of all involved skin together with implantation of the testes into the thighs and skin grafting of the bared shaft of the penis is the only curative treatment. Even though penoscrotal elephantiasis is a debilitating disease, complete surgical excision coupled with penile reconstruction has been associated with good cosmetic and functional results [62].

\section{Onchocerciasis}

This is due to the involvement of the groin by infection with Onchocerca volvulus, and the resultant changes associated with the famous acronym - 'hanging groin'. It is transmitted from the bite of a black fly called Simulium. This is commonly associated with the presence of subcutaneous nodules around the waist. Chronic inflammatory response to the micriofilariae results in obstruction of dermal lymphatics. The lymphoedema leads to the hanging groin. The disease is further characterised by the patchy depigmentation known as 'leopard skin', which may affect various parts of the body including the genitalia.

\section{Treatment}

Initial medical treatment using diethylcarbamazine $30 \mathrm{mg}$ daily for 3 days has been shown to be effective in mild cases of microfilariae infection. Unlike elephantiasis of the scrotum, where the large size of the scrotum is a source of social embarrassment for the sufferer, in onchocerasis, the lesions rarely get so big. However, for cosmetic reasons, the redundant skin and subcutaneous tis-
Table 3. Summary of medical treatment of helminthic parasitic diseases of the genitourinary system

\begin{tabular}{lll}
\hline Type of organisms & Disease & Medical treatment \\
\hline $\begin{array}{l}\text { Cestodes } \\
\text { (E. granulosus) }\end{array}$ & hydatid & $\begin{array}{l}\text { albendazole } 400 \mathrm{mg} \text { twice } \\
\text { daily, praziquantel } 40 \mathrm{mg} / \\
\mathrm{kg} / \text { day (before surgery) }\end{array}$ \\
\hline $\begin{array}{l}\text { Trematodes } \\
\text { (S. haematobium) }\end{array}$ & schistosomiasis & $\begin{array}{l}\text { praziquantel } 60 \mathrm{mg} / \mathrm{kg} \text { or } \\
\text { artemether } 6 \mathrm{mg} / \mathrm{kg}, \\
\text { niridazole } 7.5 \mathrm{mg} / \mathrm{kg}+ \\
\text { metriphonate } 12.5 \mathrm{mg} / \mathrm{kg}\end{array}$ \\
\hline $\begin{array}{l}\text { Nematodes } \\
\text { (W. bancrofti) }\end{array}$ & chyluria & $\begin{array}{l}\text { albendazole } 400 \mathrm{mg} \mathrm{twice} \\
\text { daily, sclerotherapy using } \\
5 \% \text { povidone iodine }\end{array}$ \\
& elephantiasis of & $\begin{array}{l}\text { diethylcarbamazine } \\
\text { (suramin) } 0.5-2 \mathrm{~g} / \mathrm{kg}, \\
\text { albendazole }\end{array}$ \\
\hline Scrotum & onchocerciasis & \begin{tabular}{l} 
ivermectin $150 \mu \mathrm{g} / \mathrm{kg}$ \\
\hline
\end{tabular} \\
\hline
\end{tabular}

sue can be excised. Any defect can be covered using skin grafts or flaps. As for elephantiasis of the scrotum, there is no effective medical treatment for established genital onchocerciasis, although patients found to have earlystage infection may benefit from ivermectin tablets.

Table 3 shows a summary of the medical treatments available for major helminthic parasitic diseases of the urinary tract.

\section{Non-Helminthic Parasitic Diseases of the Genitourinary Tract}

The following non-helminthic parasites can affect the genitourinary tract: Trichomonas vaginalis, P. falciparum, Entamoeba histolytica and very rarely fly larvae. Only 2 of these non-helminthic parasites deserve further consideration, the 2 protozoan parasites.

\section{Trichomonas vaginalis}

This flagellate organism is commonly found in the secretions of inflamed genital surfaces such as vaginal or prepucial skin or the urethral mucosa. The disease is commonly transmitted sexually and may involve the Cowper or Skene glands. Rarely it is the cause of chronic prostatitis or seminal vesiculitis, and even more rarely it has been reported as a cause of cystitis or even pyelitis. The protozoa are easily recognized as actively motile organisms progressing through the fluid of a 'hanging drop' wet preparation without the need for special stains. Treat- 
ment with metronidazole by pessary or by mouth (400 mg 12-hourly for 7 days) is effective.

\section{Plasmodium falciparum}

The phenomenon of black water fever is the only urological manifestation of malaria. It is due to haemoglobinuria of considerable degree resulting from the lysis of large numbers of red blood cells by an immune mechanism involving complement, and is seen only in patients who have stayed 2-3 months in an endemic area and who have been treated with inadequate doses of antimalarial. The haemoglobinuria is of sufficient degree to cause acute renal tubular necrosis in addition to other malarial symptoms, and uraemia may result. Treatment requires the use of appropriate antimalarials alongside the usual measures required to treat uraemia.

\section{Illustrative Case Reports}

Most of what has been described above has been about the features of these parasites in patients in endemic areas. With the changing economic world order, mass migration and increasing globalisation, as well as the thrill enjoyed by travellers, mostly Westerners during holidays to 'exotic' parts of the world, it is possible for some of them to contract parasitic diseases which are not found in their native countries as demonstrated by the following brief case reports.

A cerebral mass was found in a 13-year-old German girl who had spent a few years in a tropical country where Taenia solium was endemic [63]. Excisional surgery was done and histology confirmed the presence of cysticerci, the larvae of T. solium.

Following appendicectomy, schistosoma ova were found in the appendices of 3 Ghanaian immigrant residents in Italy [64]. The schistosoma lesions could easily be misinterpreted as neoplastic changes in the appendix, as schistosomiasis is never found in Europe. Similarly, migrants from schistosoma-endemic areas may present with prostatic lesions resembling prostate cancer [16]. Caucasians after visiting an endemic area for schistosomiasis may present with features suggestive of neoplastic ureteral obstruction as reported in a Caucasian woman in the UK secondary to an adult schistosoma worm in the ureter [65]. Lastly, ureteral obstruction caused by schistosomiasis of the ureter in an immigrant from Somalia based in rural USA has also been reported [66].

These cases illustrate the need for the practising urologists to remain updated on the status of important zoonosis affecting the genitourinary tract, their geographical distribution, a working knowledge of the clinical features and treatment options for these parasitic diseases.

\section{Conclusion}

Helminthic and to a lesser extent non-helminthic parasites can infest the genitourinary tract through a variety of exposures. As for other infectious agents, physicians in non-endemic areas need to be trained and updated about the clinical manifestations and management of common parasites that can infest the genitourinary system.

\section{References}

1 Patz J, Graczyk T, Geller N, Vittor A: Effects of environmental change on emerging parasitic diseases. Int J Parasitol 2000;30:13951405.

2 Chitsulo L, Engels D, Montresor A, Savioli L: The global status of schistosomiasis and its control. Acta Trop 2000;77:41-51.

3 Ross AGP, Li Y, Williams G, Jiang Z, McManus DP: Dam worms. Biologist 2001;48:121124.

4 Warren K: The pathology of schistosome infections. Helminthol Abstr Ser A 1973;42: 590-633.

5 Ross AGP, Bartley PB, Sleigh AC, Olds GR, Li Y, et al: Current concepts: schistosomiasis. N Engl J Med 2002;346:1212-1220.
6 Newman L: Worm infections fester as experts vie for fair share of funding. Lancet Infect Dis 2001;1:140.

$7 \mathrm{King} \mathrm{CH}$ : Disease in schistosomiasis haematobia. In: Mahmoud AAF (ed): Schistosomiasis. London, Imperial College Press, 2001, pp 265-295.

-8 Hatz CF, Vennervald BJ, Nkulila T, et al: Evolution of Schistosoma haematobium-related pathology over 24 months after treatment with praziquantel among school children in southeastern Tanzania. Am J Trop Med Hyg 1998;59:775-781.

$\checkmark 9$ Elsebai I: Parasites in the aetiology of cancer - bilharziasis and bladder cancer. CA Cancer J Clin 1977;27:100-106.
10 Bedwani R, Renganathan E, El Kwhsky F, et al: Schistosomiasis and the risk of bladder cancer in Alexandria, Egypt. Br J Cancer 1998;77:1186-1189.

11 Cheever AW: Schistosomiasis and neoplasia. J Natl Cancer Inst 1978;61:13-18.

$\checkmark 12$ Poggensee G, Feldmeier H: Female genital schistosomiasis: facts and hypotheses. Acta Trop 2001;79:193-210.

13 Goldsmith PC, Leslie TA, Sams V, Bryceson AD, Allason-Jones EM, Dowd PM: Lesions of schistosomiasis mimicking warts on the vulva. BMJ 1993;307:556-557.

14 Feldmeier H, Krantz I, Poggensee G: Female genital schistosomiasis: a neglected risk factor for the transmission of HIV? Trans R Soc Trop Med Hyg 1995;89:237. 
-15 Wallace DM: Urinary schistosomiasis in Saudi Arabia. Ann R Coll Surg Eng 1979;61: 265-270.

16 Al Saeed O, Sheikh M, Kehinde EO, Makar R: Seminal vesicle masses detected incidentally during transrectal ultrasound of the prostate. J Clin Ultrasound 2003;91:618-622.

-17 Gupta R, Kehinde EO, Sinan T, Al-Essa AA: Urinary schistosomiasis: urographic fixtures and significance of drooping kidney appearance. Inter Urol Nephrol 2001;33:461-465

$\checkmark 18$ Tsang VC, Wilkins PP: Immunodiagnosis of Schistosomiasis. Immunol Invest 1997;26: 175-188.

19 Al-Sherbiny MM, Osman A, Hancock K, Deelder AM, Tsang VC: Application of immunodiagnostic assays: detection of antibodies and circulating antigens in human schistosomiasis and correlation with clinical findings. AM J Trop Med Hyg 1999;60:960-966.

-20 Wang X, Li S, Zhou Z: A rapid one-step method of EIA for detection of circulating antigen of Schistosoma japonicum. Chin Med J (Engl) 1999;112:124-128.

$\checkmark 21$ Thomas H, Gonnert R: The efficacy of praziquantel against cestodes in animals. $\mathrm{Z} \mathrm{Pa-}$ rasitenkd 1977;52:117-127.

22 Brindley PJ, Sher A: The chemotherapeutic effect of praziquantel against Schistosoma mansoni is dependent on host antibody response. J Immunol 1987;139:215-220.

-23 Richter J: Evolution of schistosomiasis-induced pathology after therapy and interruption of exposure to schistosomes: a review of ultrasonographic studies. Acta Trop 2000; 77:111-131.

-24 Karanja DM, Boyer AE, strand M, et al: Studies on schistosomiasis in western Kenya. II. Efficacy of praziquantel for treatment of schistosomiasis in persons coinfected with human immunodeficiency virus. Am J Trop Med Hyg 1998;59:307-311.

$>25$ Xiao S, Shi Z, Zhou S, et al: Field studies on the preventive effect of oral artemether against schistosomal infection. Chin Med J (Engl) 1996;109:272-275.

-26 Utzinger J, N'Goran E, N'Dri A, Lengeler C, Shuhua X, Tanner M: Oral artemether for prevention of Schistosoma mansoni infection: randomised controlled trial. Lancet 2000;355:1320-1325.

-27 Shuhua X, Utzinger J, Chollet J, Endriss Y, N'Goran EK, Tanner M: Effect of artemether against Schistosoma haematobium in experimentally infected hamsters. Int J Parasitol 2000;30:1001-1006.

-28 Shuhua X, Jiqing Y, Jinying M, Huifang G, Peiying J, Tanner M: Effect of praziquantel together with artemether on Schistosoma japonicum parasites of different ages in rabbits. Parasitol Int 2000;49:25-30.

-29 Brindley PJ, Sher A: Anti-schistosomal drugs: observations on the mechanism of resistance to hycanthone, and on the involvement of host antibodies in the mode of action of praziquantel. Mem Inst Oswaldo Cruz 1987;82(suppl 4):157-161.
30 William S, Botros S, Ismail M, Farghally A, Day TA, Bennett JL: Praziquantel-induced tegumental damage in vitro is diminished in schistosomes derived from praziquantel-resistant infections. Parasitology 2001;122:6366.

31 Ismail M, Botros S, Metwally A, et al: Resistance to praziquantel: direct evidence from Schistosoma mansoni isolated from Egyptian villagers. Am J Trop Med Hyg 1999;60: 932-935.

32 King CH, Muchiri EM, Ouma JH: Evidence against rapid emergence of praziquantel resistance in Schistosoma haematobium, Kenya. Emerg Infect Dis 2000;6:585-594.

33 Ghoneim MA: Bilharziasis of the genitourinary tract. BJU Int 2002;89(suppl 1):22-30.

34 Ghoneim MA, Nabeeh A, El-Kappany A: Endourologic treatment of ureteral structures. J Endourol 1988;2:263-270.

35 Ghoneim MA, Ali-El-Dien B: Replacing the ureter by an ileal tube, using the Yang-Monti procedure. BJU Int 2005;95:455-470.

36 Ali-El-Dein B, Ghoneim MA: Bridging long ureteral defects using the Yang-Monti principle. J Urol 2003;169:1074-1077.

37 Sayegh ES, Dimmette RM: The fibrotic contracted urinary bladder associated with schistosomiasis and chronic ulceration. J Urol 1956;75:671-679.

38 Badr M, Zaher MF: The cystoplasty in the treatment of bilharzial contracted bladder. J Med Assoc 1959;42:33-35.

39 Ghoneim MA, Shoukry I: The use of ileum for correction of advanced or complicated lesions of the urinary tract. Int J Urol Nephrol 1972;4:25-33.

40 Shokeir AA, Ibrahim AD, Hamid MY, Hussien HE, Badr M: Urinary bilharzias in upper Egypt: a clinico-pathological study. East Afr Med J 1972;49:298-311.

41 Ragi I: A new look on bladder neck obstruction syndrome with evaluation of different surgical corrections: experience with 92 cases. Egypt J Urol 1960;4:67-74.

42 El-Bolkainy NM, Ghoneim MA, Mansoura MA: Carcinoma of the balharzial bladder in Egypt: clinical and pathological features. $\mathrm{Br}$ J Urol 1972;44:516-520.

43 Sammuels S, Fosmoe R: Alveolar hydatid disease with involvement of the inferior vena cava. Am Surg 1970;6:698-701.

44 Kumar PV, Jahonshali S: Hydatid cyst of testis: a case report. J Urol 1987;137:511-512.

-45 Adewunmi OA, Basilingappa HM: Primary ovarian hydatid disease in the kingdom of Saudi Arabia. Saudi Med J 2004;25:16971700.

46 Zayed AM, Abdel-Rahman AH: Isolated hydatid cyst of the kidney: diagnosis and surgical treatment. Arab J Urol 2005;3:6-12.

47 Zmerli S, Ayed M, Horchani A, Chami I, El Quakdi M, Ben Slama MR: Hydatid cyst of the kidney: diagnosis and treatment. World J Surg 2001;25:68-74.

48 Von Sinner WN: New diagnostic sign in hydatid disease: radiography, ultrasound, CT and MRI correlated to pathology. Eur J Radiol 1990;12:150-159.

49 Vargas-Serrano B, Ferreiro-Arguelles C, Rodriguez-Romero R, Marcos Del Rio N: Imaging findings in renal hydatid disease. Eur Radiol 1997;7:548-551

50 Baykal K, Onol Y, Iseri C, Kalci E, Kizilkaya $\mathrm{E}$, Inal $\mathrm{H}$, et al: Diagnosis and treatment of renal hydatid disease: presentation of four cases. Int J Urol 1996;3:497-500.

51 Rar MS: Cyst causing obstructive azoospermia. Obstructive azoospermia due to retrovesical hydatid cyst. Fertil Steril 1979;32: 706-707.

52 Rahemtulla A, Bryceson AD, McManus DP, Ellis DS: Albendazole in the treatment of hydatid disease. J R Soc Med 1987;12:39-42.

53 Horton RJ: Chemotherapy for Echinococcus infection in man with albendazole. Trans $\mathrm{R}$ Soc Trop Med Hyg 1989;83:97-102.

54 Morris DL: Albendazole treatment of hydatid disease follow-up at 5 years. Trop Doct 1989;19:178-180.

55 Horchani A, Nouira Y, Kbaier I, Attyaoui F, Zribi AS: Hydatid cyst of the kidney: a report of 147 controlled cases. Eur Urol 2000;38: 461-467.

56 Bret PM, Fond A, Bretognolle M, et al: Percutaneous aspiration and drainage of hydatid cysts in the liver. Radiology 1988;168: 617-620.

57 Zhang X, Zhu Q, Ma X, Zheng T, Li H, Zhang J, et al: Renal pedicle lymphatic disconnection for chyluria via retroperitoneoscopy and open surgery: report of 53 cases with follow-up. J Urol 2005;174:1828-1831.

$\checkmark 58$ Tan LB, Chiang CP, Huang CH, Chou YH, Wang CJ: Experiences in the treatment of chyluria in Taiwan. J Urol 1990;144:710-713.

59 PunekarSV,KelkarAR, Prem AR,Deshmukh HL, Gavande PM: Surgical disconnection of lymphorenal communication for chyluria: a 15-years experience. Br J Urol 1997;80:858864 .

60 Hornberger BJ, Elmore JM, Roehborn CG: Idiopathic scrotal elephantiasis. Urology 2005;389:e14-e15.

61 Mc Dougal SW: Lymphodema of external genitalia. J Urol 2003;170:711-716

62 Kuepper D: Giant scrotal elephantiasis. Urology 2005;65:389

63 Klotz P, Tappe D, Abele-Horn M, GlarmuthMetz M, Sorensen N, Speer CP, Grischick HJ: Cerebral mass in a 13 year old girl following long term sojourn in the Tropics. J Med Microbiol 2006;55:345-347.

64 Rivasi F, Pampiglione S: Appendicitis associated with presence of Schistosoma haematobium eggs: an unusual pathology for Europe. APMIS 2006;114:72-76.

65 Ajit MK, Groenwald EA, Speakman M: An unusual presentation of genitourinary schistosomiasis in a Caucasian woman in the UK. Ann R Coll Surg Engl 2005;87:481-483.

66 Neal PM: Schistosomiasis: An unusual cause of ureteral obstruction: a case history and perspective. Clin Med Res 2004;4:217-227. 